\title{
Crônicas da urgência: os desafios das ciências na criação do futuro no Antropoceno
}

Alice Fernandes Freyesleben ${ }^{1}$

Doutoranda do Programa de Pós-Graduação em História

Universidade Federal do Paraná

Curitiba - PR

\section{Resumo}

$O$ presente artigo tem como objetivo refletir acerca da renovação epistemológica e dos desafios científicos suscitados pela emergência do colapso ambiental. Para tanto, foi dividido em quatro partes. Na primeira, tendo como base o pensamento de Danowski, Viveiros de Castro e Latour, propõe uma reflexão filosófica sobre o esgotamento paradigmático dos modelos que constituíram as ciências modernas e analisa os novos objetos de estudo transdisciplinares que caracterizam o Novo Regime Climático, para usar a terminologia de Latour. No segundo momento, são analisados embates referentes à formalização do termo Antropoceno para designar a nova época geológica e sua decorrente inserção na Escala do Tempo Geológico. Em seguida, o foco incide sobre as considerações acerca do suposto caráter generalizante do termo Antropoceno para designar a época presente. Para isso, utiliza-se principalmente de conceitos desenvolvidos pelo historiador Jason W. Moore e pela filósofa Donna Haraway. A quarta parte indica, a partir das colocações de Reinhart Koselleck e François Hartog, as repercussões do Antropoceno sobre o regime de historicidade da sociedade global capitalizada na contemporaneidade. Ao mesmo tempo, reflete sobre alguns dos desafios enfrentados pela ciência, enquanto instituição, na tarefa de convencer a opinião pública de forma a mobilizá-la para que aumente a pressão sobre as instâncias políticas aptas a tomar medidas que mitigariam dos efeitos do Antropoceno.

\footnotetext{
${ }^{+}$Chronicles of urgency: the challenges of science in creating the future in the Anthropocene

* Recebido: junho de 2020. Aceito: outubro de 2020.

${ }^{1}$ E-mail: alice.freyesleben@gmail.com
} 
Palavras-chave: Antropoceno; Novo Regime Climático; Época Geológica; Desafios Cientificos; Regime de Historicidade.

\begin{abstract}
This article aims to reflect about the epistemological renewal and about the scientific challenges raised by the emergence of environmental collapse. For this, it was divided into four parts. In the first, based on the thoughts of Danowski, Viveiros de Castro and Latour, it analyzes the paradigmatic exhaustion of the models that has constituted modern sciences and takes into account the new transdisciplinary objects of study that characterize the New Climate Regime, to speak with Latour. Secondly, it analyzes discussions regarding the formalization of the term Anthropocene to designate the new geological epoch and its consequent insertion on the Geological Time Scale. Then, the focus is on the supposed generalizing character of the term Anthropocene to designate the present epoch. For this, it uses the concepts developed by the historian Jason W. Moore and the philosopher Donna Haraway. Based on the statements of Reinhart Koselleck and François Hartog, the fourth part indicates how the repercussions of the Anthropocene are operating on the regime of historicity of the global capitalized society. in contemporary times. Withal, it evaluates some of the main challenges faced by science as an institution in the task of convincing public opinion in order to mobilize it to increase the pressure on policies able to take measures that would mitigate the effects of the Anthropocene.
\end{abstract}

Keywords: Anthropocene; New Climate Regime; Geological Era; Scientific Challenges; Regime of Historicity.

\title{
I. Introdução
}

E cada movimento que um de nós faz, todos fazemos. Foi-se a ideia de que cada um deixa sua pegada individual no mundo; quando eu piso no chão, não é o meu rastro que fica, é o nosso. E o rastro de uma humanidade desorientada, pisando fundo. Um nenezinho no colo da mãe balança a perninha e afunda o chão. Porque esse neném, para circular no mundo que vivemos hoje, vai usar produtos de higiene, fraldas tecidos, materiais que, em algum lugar, estão comendo a Terra. Involuntariamente ele já está predando o planeta (KRENAK, 2020, p. 96). 
Ao longo da história, as escatologias - narrativas relativas à sorte final daquilo que chamamos de "mundo" - sempre estiveram presentes no imaginário dos mais diferentes povos. Tal como observam Débora Danowski e Eduardo Viveiros de Castro, o "fim do mundo é um tema aparentemente interminável - pelo menos, é claro, até que ele aconteça” (2014, p.11). De fato, o fim do mundo pode se mostrar muito mais complexo do que se pode alcançar à primeira vista. Afinal, como sublinham os autores "há muitos mundos no Mundo" (DANOWSKI; VIVEIROS DE CASTRO, 2014, p.156). Nesse sentido, o intelectual indígena Ailton Krenak não cansa de repetir em suas inúmeras aparições públicas que o "mundo" das populações autóctones do continente americano já "acabou" há mais de quinhentos anos, mas essas populações seguem resistindo e vivem.

Atualmente, os debates sobre o fim da humanidade e do mundo tal como os conhecemos adentraram com força também o campo da ciência. Se antes as grandes mentes estiveram ocupadas em encontrar formas de expandir o conhecimento e progredir tecnológica, econômica e socialmente, a chegada do século XXI trouxe consigo uma profunda alteração nas próprias concepções de conhecimento, economia e progresso. Frente ao desafio que agora se apresenta com maior intensidade do que nunca, tais concepções não parecem oferecer respostas suficientes: como sobreviver à mudança, já em curso, das condições ambientais em nível planetário? Isto é, como sobreviveremos ao avanço do Antropoceno - terminologia, derivada do prefixo grego Anthropos, usada para designar a época em que os humanos se transformaram em uma força geológica capaz de alterar as condições físicas, químicas e biológicas do planeta - sem que coloquemos o futuro que se prepara, para usar as palavras da filósofa Isabelle Stengers (2015, p.12), "sob o signo da barbárie"? As perguntas assumem um caráter de urgência, uma vez que, conforme atestam cientistas atuantes nas mais diversas áreas, espalhados por todos os países, a nova época não oferecerá as condições de habitabilidade de sua época predecessora, o Holoceno.

A passagem do Holoceno para o Antropoceno ainda está sendo investigada e teorizada. Há incertezas e discordâncias acerca da inclusão do Antropoceno entre os geólogos, únicos que que detêm autoridade científica para alterar oficialmente a Escala do Tempo Geológico. Mas, ainda que não seja oficialmente reconhecido como época geológica, profissionais de distintas áreas têm defendido a cientificidade do termo para designar o conjunto das novas relações que emergem à medida que conhecimentos sobre o colapso ambiental em curso se acumulam. Conforme destaca o historiador Dipesh Chakrabarty (2018), Antropoceno é a única expressão do âmbito da geologia que foi examinada e debatida entre intelectuais que não têm qualquer conhecimento sobre Estratigrafia, o ramo dedicado ao estudo e datação dos processos formadores das camadas dos estratos rochosos. Questões acerca do trajeto histórico que transformou os seres humanos em uma força geológica, capaz de rivalizar com outras grandes forças da natureza e modificar as condições planetárias, têm sido vividamente debatidas entre historiadores, sociólogos, filósofos e antropólogos.

Nesse contexto, se a suposta neutralidade e objetividade da ciência já vinham sendo 
questionadas, desde pelo menos a apropriação dos avanços tecnológicos pela indústria da guerra, a entrada no Antropoceno termina de pôr em xeque paradigmas e limites disciplinares que organizaram e constituíram as epistemologias modernas. Saímos de um "Antigo Regime", no qual as noções de ciência e política pareciam estar separadas (bem como as noções de natureza e cultura) e estamos no início de um "Novo Regime Climático", dirá Bruno Latour (2020). O autor ressalta a importância do esclarecimento de que a situação atual não é uma crise, uma vez que a ideia de crise remete a algo transitório, temporário. Não é o caso do Novo Regime. "Estávamos acostumados a um mundo; agora, passamos, mudamos para outro" (LATOUR, 2020, p. 23). Durante a série de conferências das Gifford Lectures, em 2013, o filósofo procurou deslindar como a mutação nas condições climáticas está modificando a percepção (essencialmente moderna) sobre a existência de um objeto chamado Natureza inerte e passível de investigação, dominação e exploração econômica pelo sujeito Humano. Aquilo que havia sido

[...] considerado líquido e certo, o solo sobre o qual sua história sempre se desenrolara, tornou-se instável. Como se o cenário tivesse subido ao palco para compartilhar a trama com os atores. A partir desse momento, tudo muda no modo de contar histórias, a ponto de incluir na política o que antigamente pertencia à natureza - figura que, por tabela, se torna um enigma cada dia mais indecifrável (LATOUR, 2020, p. 18).

À falência dos modelos epistemológicos pautados na ideia de repartição de saberes autores como o cientista alemão Hans Joachim Schellnhuber (1999) opuseram a emergência de um novo paradigma, algo que equivaleria à "Segunda Revolução Copernicana." Na nova perspectiva paradigmática, o planeta deveria ser analisado como um único grande sistema, o Sistema Terra (Earth System), composto pelo conjunto dos elementos físicos, químicos, biológicos, sociais, econômicos e culturais, assim como pelos processos e interações desses elementos que juntos determinam o estado e a dinâmica da Terra. Com efeito, institutos de pesquisa e intuições de ensino passaram a convidar cientistas de "áreas" diferentes para constituir conjuntamente os parâmetros da nova ciência unificada. Dessa maneira, os chamados "cientistas da Terra" têm buscado compreender historicamente a mudança global (Global Change) e delimitar possíveis efeitos futuros dessa mudança.

Nesse sentido, observa-se a disseminação de certo Zeitgeist, relacionado à ampliação da consciência do colapso ambiental, que anima movimentos sociais, cúpulas da ONU, acordos diplomáticos, debates acadêmicos, manifestos políticos e científicos. Uma vasta bibliografia, que se avoluma quase diariamente, tem frisado que a crise atual não fica restrita ao âmbito ambiental, mas abarca a própria forma como a sociedade contemporânea percebe sua historicidade. O passado é então interpretado como uma coleção de erros e o futuro assume cada vez mais o signo do temor. Isso, pois, em comparação com o velho medo da guerra nuclear, a relação do Antropoceno com o agenciamento humano é mais complexa, já 
que o "Antropoceno, poder-se-ia dizer, é uma consequência não intencional das escolhas humanas", como bem destacou o historiador Chakrabarty (2013, p. 13).

Isso posto, o presente artigo pretende reunir alguns dos principais debates e reflexões que envolvem a ideia do advento de uma nova etapa temporal, tanto histórica quanto geológica, e os desafios teóricos que dela emergem. Para tanto, divide-se em duas partes: a primeira, dedica-se à análise das questões científicas que determinarão o reconhecimento ou não do Antropoceno como época geológica; a segunda, procura lançar luz sobre alguns desdobramentos políticos e filosóficos que envolvem as reflexões sobre o Antropoceno. No entanto, como será especificado, a própria noção de Antropoceno modifica os tradicionais escopos disciplinares, de modo que as duas partes do presente artigo partilham elementos e impasses comuns. Os estudos sobre causas, início e repercussões dessa época se referem de forma conjunta à história humana, à história geológica e à relação entre as duas, de maneira que climatologistas, biólogos, geólogos, oceanógrafos, ecólogos, arqueólogos, filósofos, sociólogos, historiadores, críticos literários, artistas, antropólogos e demais cientistas precisam refletir sobre matrizes energéticas, assimetrias sociais, causas de catástrofes "naturais", exploração de recursos, migrações motivadas por alterações climáticas, políticas públicas e justiça ambiental. E é sobre isso que Bruno Latour (2020) reflete quando destaca que a divisão entre ciências naturais e ciências humanas efetivada no século XIX se torna cada vez mais confusa na medida que adentramos com mais força no Novo Regime Climático. De fato, o emprego do substantivo Natureza para se referir a tudo aquilo que está "fora" do mundo humano (social ou cultural) tem se mostrado tão polêmico quanto o adjetivo "natural" para designar situações adequadas ao modelo dominante: masculino, branco, capitalista, heterossexual, cristão. "Somos forçados a redistribuir por completo o que antes se chamava de natural e o que se chamada de social ou simbólico" (LATOUR, 2020, p. 195).

\section{Os desafios da periodização}

Periodizar é uma operação complexa que engendra amplas possibilidades de questionamentos e discordâncias, tanto no âmbito da história como no da geologia. Volumosas discussões e controvérsias costumam marcar os debates sobre a emergência ou fim de um período ou sobre novas formas de escalonar o tempo. No campo disciplinar da História, nunca houve necessidade de se definir com precisão termos como "época", "era", "idade", "período" etc., de forma que entre os historiadores esses termos sempre foram empregados como bastante liberdade. Entretanto, entre os profissionais dedicados à Estratigrafia, terminologias como "período", "era" e "época" não podem ser utilizadas, à maneira dos historiadores, como se fossem sinônimos.

Com efeito, o desenvolvimento da estratigrafia e o aumento de precisão de seus cálculos transformou nossa concepção sobre a idade do planeta justamente pelo rigor com que os geólogos tratam as operações relacionadas à nomenclatura desde a estruturação dos critérios de funcionamento dessa ciência no século XIX. A formalização de consensos e 
padronização das ferramentas teóricas e modelos de trabalho teve início 1878, em Paris, na primeira edição do Congresso Geológico Internacional (International Geological Congress, IGC). Na ocasião, foram definidos os assuntos que seriam discutidos três anos depois, no segundo evento na Itália. Assim, o programa geral do Segundo Congresso Geológico Internacional, realizado em Bolonha entre 25 de setembro e 5 de outubro de 1881, teve como objetivo a padronização dos símbolos, nomenclaturas, cronologias geológicas e marcadores estratigráficos. Nesse importante encontro, o grupo, composto por cientistas de vinte e duas nacionalidades, estipulou as divisões na Escala do Tempo Geológico, estabelecendo o que seria uma época geológica e definindo que a época geológica na qual vivia se chamaria Holoceno (VAI, 2004). Tal época, ulterior à época do Pleistoceno, teve início há aproximadamente 11700 anos, quando a última glaciação terminou (WATERS et al., 2016). É importante destacar que a padronização de marcadores estratigráficos (aspectos, seções ou pontos distinguíveis nos estratos rochosos), iniciada em 1881, como critério de determinação das divisas na escala do tempo geológico, foi amplamente adotada ao longo da constituição da geologia enquanto ciência. Os chamados Global Boundary Stratotype Section and Points (GSSPs), ou apenas golden spikes, desde então têm sido buscados, e, uma vez definidos, servem como base para a determinação de processos e eventos formadores da crosta terrestre por profissionais do mundo inteiro.

Já em 2012, durante a trigésima quarta edição do Congresso Geológico Internacional em Brisbane, Austrália, e em 2016, ao longo da trigésima quinta, transcorrida na Cidade do Cabo, na África do Sul, foram estabelecidas orientações para que os cientistas pertencentes ao Grupo de Trabalho do Antropoceno (Anthropocene Working Group, AWG) ${ }^{2}$, formado em 2009, pudessem concluir sua tarefa: definir os critérios que caracterizam o Antropoceno como época geológica.

A ideia de que a época do Holoceno teria chegado ao fim já havia sido proposta em 2000 pelo químico Paul Crutzen e pelo biólogo Eugene Stoermer. Todavia, o termo Antropoceno ganhou notoriedade apenas em 2002, quando Crutzen publicou seu famoso artigo Geology of Mankind na prestigiosa revista Nature. A hipótese inicial do químico afirmava que "por causa das emissões antropogênicas de dióxido de carbono, o clima global poderá distanciar-se significantemente do comportamento natural por muitos milênios" (CRUTZEN, 2002, p. 23). Dessa forma, para Crutzen, o termo "Antropoceno" deveria ser adotado para indicar a "época geológica presente, dominada por humanos, que complementa o Holoceno" (CRUTZEN, 2002, p. 23).

\footnotetext{
2 O AWG foi criado em 2009 por Jan Zalasiewicz, professor e pesquisador do Departamento de Geologia da Universidade de Leicester. O grupo atua desde então sob a autoridade da Subcomissão de Estratigrafia Quartenaria (Subcommission on Quaternary Stratigraphy, SQS), que por sua vez faz parte da Comissão Internacional de Estratigrafia (International Commission on Stratigraphy, ICS), que responde à União Internacional das Ciências Geológicas (International Union of Geological Sciences, IUGS), a principal organização científica voltada ao estudo estratigráfico e geológico em escala global. Para obter informações sobre os cientistas que compõe o grupo e a acessar as principais publicações, $\mathrm{C} f$. $<\mathrm{http}$ //quaternary.stratigraphy.org/working-groups/anthropocene/>. Acesso em: 25 set. 2020.
} 
Todavia, passados vinte anos desde a proposta inicial de Crutzen e Stoermer e mais de dez desde a criação do AWG, a Escala do Tempo Geológico ainda não foi alterada em razão de empecilhos técnicos, teóricos e divergências entre os cientistas que dirigem as instituições encarregadas da formalização do termo e, oficialmente, ainda vivemos na Idade Megahayana da época do Holoceno. Os debates sobre os critérios capazes de definir o início da nova época e sobre a real utilidade científica de tal definição prosseguem. Embora o volume de evidências recolhidas pelos cientistas do AWG sobre a existências de indicadores suficientes para a oficialização do Antropoceno esteja aumentado consideravelmente (WATERS et. al., 2016), questionamentos acerca do evento ou processo deflagrador da época persistem.

Em artigo seminal intitulado The Anthropocene: conceptual and historical perspectives, publicado no dossiê da Philosophical Transactions of The Royal Society, de 2011, quatro membros do AWG - o historiador ambiental J. R. McNeill, o filósofo da ciência Jacques Grinvald, e os químicos Paul Crutzen e Will Steffen - sintetizaram algumas das propostas de datação do Antropoceno e avaliaram os prós e os contras das hipóteses então consideradas. Levantamento semelhante foi realizado pelo pesquisador do Environmental Change Institute da Universidade de Oxford, Yadvinder Malhi, publicado no periódico Annual Review of Environment and Resources, em 2017, com o título The Concept of Anthorpocene.

Algumas propostas de datação associam a primeira onda de extinção da megafauna e a ascensão dos hominídeos ocorridas no Pleistoceno (SMITH et al., 2018) com o que Malhi (2017, p. 25.12) nomeia de Early Anthropocene (Antropoceno Inicial). Os membros do AWG rejeitaram de saída tal hipótese afirmando que não é possível formalizar uma época geológica sem ter em vista um quadro de mudança global (Global Change). E, por mais que a extinção de grandes mamíferos pelo gênero homo tenha provocado impactos nos habitats onde viviam, não há evidências de que esse evento tenha tido "impacto considerável no funcionamento do Sistema Terrestre como um todo" (STEFFEN et. al., 2011, p. 847).

Outra proposta de datação que recua milênios em busca do começo da "época dos humanos" data seu princípio junto à Revolução Neolítica. Segundo essa concepção, há cerca de 8000 anos assistiu-se ao grande desenvolvimento da agricultura no oriente, fato que ocasionou desmatamento de áreas extensas e a subsequente liberação grandes quantias de $\mathrm{CO}_{2}$. Esse desmatamento primordial poderia ter revertido a tendência de queda na concentração de $\mathrm{CO}_{2}$ estabelecida no Holoceno. Há registros de um leve aumento da concentração de $\mathrm{CO}_{2}$ de 5 a 10 ppm nesse período, mas os cientistas do AWG (STEFFEN et al., 2011, p. 847) problematizam o fato de que se o pequeno aumento ocorrido entre $5000 \mathrm{e}$ 8000 anos atrás tivesse provocado elevação significativa na temperatura média global, as concentrações de $\mathrm{CO}_{2}$ atuais deveriam ter provocado um aquecimento bem superior ao observado. Nesse sentido, Malhi destaca que a delimitação do Antropoceno há milhares de anos acaba por reduzir o conceito "a uma metáfora para todas as interações humanas com o 
meio ambiente" (2017, p. 25.13).

O século XVI, por sua vez, também já foi candidato a marco inicial do Antropoceno (LEWIS; MASLIN, 2015). Segundo essa hipótese, os elevados índices de mortandade das populações autóctones do continente americano, após a chegada dos europeus, ocasionaram a expansão das florestas sobre terras agrícolas abandonadas e resultou num decréscimo nas concentrações de $\mathrm{CO}_{2}$ atmosférico de 7-10 ppm entre 1570 e 1620. Tal redução, que de fato é aferida por meio de estudos do gelo antártico, poderia então servir como GSSP (DULL et al., 2010, Apud. MALHI, 2017, p. 25.16). Todavia, especialistas afirmam que flutuações na concentração de $\mathrm{CO}_{2}$ atmosférico desse tipo podem ter ocorrido em diversos momentos do Holoceno (MALHI, 2017, p. 25.16). Assim, a proposta foi contestada em razão da imprecisão dos dados atmosféricos do período como marcadores estratigráficos.

Até agora, as noções de Global Change, Earth System, Planetary Bounderies (limites planetários), Humam Imprint (alguns autores utilizam o termo Human footprint, "pegada humana") e Great Acceleration (Grande Aceleração), desenvolvidas pela primeira vez no artigo de 2007 assinado por Steffen, Crutzen e McNeill e publicado na revista Ambio - The Anthopocene: Are Humans Now Overwhelming the Great Forces of Nature? - têm prevalecido como norteadoras gerais dos debates científicos sobre o Antropoceno. Mas, o que pode ser considerado "impressão humana"? Quais processos a deflagram? Como pode ser aferida pela estratigrafia? Quais critérios devem ser usados para definir os limites planetários? É cientificamente possível acomodar todos os processos inorgânicos, orgânicos e sociais que ocorrem no planeta em um único sistema? (VEIGA, 2019) A complexidade inerente a essas noções provoca discordâncias na comunidade cientifica.

Uma larga fortuna crítica (que só se amplia) vem tentando encontrar respostas satisfatórias para essas perguntas. Nos trabalhos de 2007 e 2011 acima mencionados, os autores defendem que o Antropoceno teria se iniciado com a industrialização ocorrida entre os séculos XVIII e XIX, considerada um dos mais importantes episódios na história do Sistema Terra, visto que as transações químicas entre matéria viva e matéria inerte foram modificadas pela difusão do carvão mineral como fonte de energia (STEFFEN et al., 2007; 2011). Antes, todas as fontes de energia utilizadas pelos seres vivos complexos eram provenientes da energia primária do Sol, que, além de fornecer energia para a fotossíntese das plantas e algas que alimentam os animais, impulsiona também a circulação atmosférica e o ciclo hidrológico (STEFFEN et al., 2011, p. 849). De acordo com os artigos, mesmo que antes da Revolução Industrial diversos instrumentos técnicos já fossem empregados para a captação de energia, como moinhos de água e vento, tração animal e lenha, esses processos de transmissão energética engendravam perdas irremediáveis. A título de exemplo, os membros do AWG salientam que as plantas sintetizam menos de $1 \%$ da radiação solar durante a fotossíntese e quando os animais as comem só absorvem cerca de 10\% da energia armazenada nelas. Sob tal lógica, percebem a difusão dos combustíveis fósseis como uma forma inédita de ampliação do acesso à energia solar, uma vez que tanto o carvão mineral quanto o petróleo e o gás natural 
são "um vasto estoque de energia solar do passado que se acumulou com dezenas ou centenas de milhões de anos de fotossíntese" (STEFFEN et al., 2011, p. 848). Ademais, em razão de sua mobilidade - podem ser extraídos e transportados por longas distâncias - os combustíveis fósseis possibilitaram que as sociedades industriais passassem a usar quatro ou cinco vezes mais energia do que as sociedades agrárias, estas, por sua vez, já usavam três ou quatro vezes mais energia do que as sociedades de caçadores-coletores (STEFFEN et al., 2011, p. 848849). Dessa forma, a rápida expansão do uso desse tipo de combustível permitiu o desenvolvimento de operações técnicas já existentes e criação de várias novas. Isso posto, nos textos de 2007 e de 2011, os cientistas do AWG defenderam a tese de que o período que vai da primeira metade do século XIX até 1945 deveria ser considerado o "primeiro estágio do Antropoceno", no qual a concentração de $\mathrm{CO}_{2}$ aumentou cerca de 25 ppm (partes por milhão). Esse número, de acordo com os autores, é suficiente para ultrapassar o limite superior de variação natural do Holoceno e, assim, fornece a primeira evidência de que as atividades humanas estavam afetando o planeta em escala global (STEFFEN et al., 2007, p. 616). O artigo de 2011, mais extenso e ambicioso, chega a sugerir que o ano 1800 d.C. seja considerado o início oficial do Antropoceno. E afirma que a proposta de utilizar uma datação cristã em lugar de "BP" Before Present (antes do presente) como no caso de outros períodos geológicos é intencional e visa salientar a importância histórico-geológica dos eventos modernos para a entrada nesse período. (STEFFEN et al., 2011, p. 849).

Ao que tudo indica, a ampliação dos estudos pelo Grupo de Trabalho e a formulação de modelos mais precisos e bem alimentados pelos dados recentes modificou a posição dos autores desde a publicação dos referidos artigos. Os debates sobre a cientificidade dos marcos estratigráficos amadureceram e os registros da concentração de $\mathrm{CO}_{2}$ atmosférico do século XIX como critério de demarcação da nova época geológica foram descartados conforme pode ser aferido na página do $\mathrm{AWG}^{3}$, que disponibiliza as resoluções do $35^{\circ}$ Congresso Geológico Internacional. Atualmente, a proposta que lidera entre as mais prováveis para delimitação inicial estabelece o intervalo compreendido entre 1945 e 1950 como o início do Antropoceno. Os GSSPs capazes de assinalar o início da época seriam os radionuclídeos artificiais que passaram a se precipitar em diversas regiões do planeta depois da difusão da tecnologia termonuclear (WATERS et al., 2018). Essa hipótese, que encontra respaldo entre profissionais da estratigrafia (ZALASIEWICZ et al., 2017; WATERS et al., 2018), passou a ser defendida também por J. R. McNeill desde a publicação de The Great Acceleration: na Envirormental History of the Antrhropocene (2014), livro escrito em parceria com o ecólogo Peter Engelke, que analisa o aumento exponencial do uso de energia, a produção de resíduos e o crescimento colossal da população humana após 1950.

A atual proposta de formalização da nova época geológica discutida pelo Grupo de Trabalho do Antropoceno considera também outros componentes químicos de origem

${ }^{3} \mathrm{Cf}$. < http://quaternary.stratigraphy.org/working-groups/anthropocene/>. Acesso em: 28 set. 2020. 
antrópica como concreto e partículas de plástico que atualmente podem ser encontradas nos sedimentos que estão começando a se acumular por todo planeta. E, nesse sentido, a constituição de uma "tecnostratigrafia" poderia ajudar na caracterização do Antropoceno como nova época geológica marcada por uma mudança radical na acumulação de materiais nos extratos terrestres (ZALASIEWICZ et al., 2014). Todavia, a investigação da disseminação acelerada desses "tecnofósseis" a partir da metade do século XX exige uma verdadeira renovação paradigmática da estratigrafia, antes "acostumada" a lidar com processos que podiam durar bilhões de anos, agora compelida a dispor seus golden spikes em intervalados menores do que um século.

A análise da proposta de formalização da nova época geológica deveria ter sido apresentada pelo Grupo de Trabalho do Antropoceno entre os dias 2 e 8 de março de 2020, em Nova Déli, durante a $36^{a}$ edição do Congresso Geológico Internacional. Entretanto, a pandemia do Covid-19 impediu a realização do evento, que foi adiado para a metade de agosto de 2021. As expectativas são grandes dos dois lados, tanto entre os que defendem o reconhecimento técnico da nova época quanto entre os que resistem à proposta. Com efeito, não há garantias de que alguma resposta definitiva saia do conclave. Conforme explica o

geólogo norte-americano Stanley C. Finney (um dos membros da Comissão Internacional de Estratigrafia, órgão responsável por acatar ou não a proposta), as questões relativas ao Antropoceno são tão emaranhadas que qualquer que seja a fronteira escolhida para a época geológica, ela será difusa, uma vez que o Antropoceno suporta múltiplos antecedentes lentos e longas consequências, assim como ocorre com o Renascimento ou com outros períodos da história humana. A encruzilhada de temporalidades e historicidades torna a tarefa da periodização geológica (que já não é simples) da "época dos humanos", especialmente complicada e as divergências servem de argumento contra sua adoção formal como época geológica (FINNEY; EDWARDS, 2016).

\section{A busca por um nome potente}

Ainda não se sabe com exatidão se o Novo Regime Climático corresponde a um sinal estratigráfico suficientemente claro para ser designado oficialmente como época geológica. Entretanto, a concretude das questões e desafios que emergem do colapso ambiental em curso são incontestes. Uma delas é a crítica ao termo Anthropos (do grego "humano") em referência à “espécie humana”. Uma abstração profundamente genérica e a-histórica que, de acordo com distintos pensadores, pode contribuir para diluir as responsabilidades históricas que provocaram a presente situação. Questiona-se se a potência do nome Antropoceno não seria justamente sua capacidade de homogeneizar a causa de um problema que historicamente é branca, capitalista e anglofônica. Essa problemática ocupa sobretudo filósofos, historiadores, sociólogos, antropólogos que insistem não ser possível enfrentar os desafios impostos pelo Novo Regime Climático sem que se considere a forte relação entre processos políticos, econômicos e sociais e as alterações climáticas, ecológicas e geológicas. De forma análoga, 
defende-se que lidar com as desigualdades e com a violência histórica inscritas na própria constituição da "humanidade" nos obriga a abandonar o etnocentrismo naturalizado na ideia de humanidade. "Somos mesmo uma humanidade?", questiona o pensador indígena Ailton Krenak (2019, p. 12). É historicamente viável falar em Anthropos quando o "liquidificador chamado humanidade" (KRENAK, 2019, p. 14) transformou e ainda transforma comunidades, que viveram por milhares de anos em habitats como campos e florestas, em "pobres" espalhados pelas periferias das cidades?

O historiador Jason W. Moore (2016) defende que a expressão Capitaloceno pode definir melhor a situação planetária atual. Segundo Moore, o capitalismo não se configura apenas como um sistema econômico utilizado por humanos, mas como uma verdadeira ecologia mundial de poder, capital e natureza que implica todas as espécies e processos físicoquímicos. A ecologia mundial capitalista (capitalist world-ecology) é uma maneira de distribuição e funcionamento da teia da vida (web of life), ou seja, uma forma de organizar a vida e o planeta (MOORE, 2016, p.5-9). Nesse sentido, o autor dirige sua análise às transformações ocorridas na Inglaterra e na Holanda ao longo do século XVI, quando o extrativismo orientado para acumulação infinita de capital se consolida. Para Moore, a chave de leitura apropriada para entender a saída das condições planetárias oferecidas pelo Holoceno foi a mudança promovida pelo capitalismo que transformou o mundo em depósito de natureza-barata (MOORE, 2016) e não o uso de combustíveis fósseis por si só. Na esteira de Moore, Justin McBrien argumenta que o acúmulo capitalista se pauta em um projeto orientado para a extinção das distintas formas de vida que segue em ritmo acelerado. Nesse sentido, a noção de Capitaloceno dá lugar a noção de Necroceno (McBRIEN, 2016).

A filósofa Donna Haraway é outra autora que questiona a dimensão teleológica da ideia de que o desenvolvimento tecnológico e o uso de combustíveis fósseis, como destino histórico da "humanidade" fadada ao "progresso", determinaram a histórica geológica. Segundo a autora, esse tipo de determinismo percebe o capitalismo como algo "transcendente". (HARAWAY, 2016a). Durante uma conversa em outubro de 2014 na Universidade de Aarhus, na Dinamarca (publicada em 2016 com o título Anthropologists Are Talking About the Anthropocene), a autora e seus interlocutores sugeriram que ao invés de Antropoceno, a época atual poderia ser chamada de Plantationoceno, em virtude dos impactos devastadores que as áreas ocupadas por pastos, latifúndios monocultores, extrativismo madeireiro fazendas provocam nos biomas e ciclos físico-químicos em escala planetária. A força histórica desse termo residiria ainda no fato da monocultura baseada na mão de obra escravizada ter sido o modelo e o motor de todos os outros sistemas de produção capitalistas modernos (HARAWAY et al., 2016).

Mais do que um sinal incrustado nas rochas do planeta, o ponto de inflexão do Holoceno para o Antropoceno precisa ser considerado um "evento-limite" que marca graves descontinuidades (HARAWAY, 2016b). Como uma das mais atuantes críticas do termo Antropoceno, Haraway insiste que é necessário evocar novos tipos de pensamento que se 
afastem da premissa da excepcionalidade do humano para que consigamos visualizar saídas radicais da narrativa antropocêntrica: o homem que modifica a paisagem do mundo à medida que promove seu desenvolvimento tecnológico. Tentando responder a tal urgência, a autora criou a ideia do Cthulhuceno, inspirada no conto "O chamado de Cthulhu", de H.P. Lovecraft. $\mathrm{Na}$ obra ficcional, alguns humanos têm suas mentes comprometidas durante um ritual para o deus Cthulhu e, com isso, vislumbram uma realidade diferente da que conheciam (KLEBIS, 2014). A época atual, o Cthulhuceno, seria, então, o momento de vislumbrar outras realidades, de "desestabilizar mundos de pensamentos, com mundos de pensamentos" (HARAWAY, Apud. KLEBIS, 2014). A filósofa norte-americana ressalta que tal proposta não deve ser interpretada como uma metáfora ou utopia teórica. Viver no Cthulhuceno não é praticar uma transcendência, mas "unir forças para reconstituir refúgios, para tornar possível uma parcial e robusta recuperação e recomposição biológica-cultural-política-tecnológica, que deve incluir o luto por perdas irreversíveis" (HARAWAY, 2016b).

Com efeito, teóricos decoloniais advertem que o nome Antropoceno pode ser uma ferramenta para apagar a colonialidade que atravessa a suposta "época dos humanos" (MILANEZ; PINTO, 2019). Essa corrente crítica destaca que a colonialidade não se encerrou com as independências dos países do chamado "Sul Global". Pelo contrário, muitos países do Sul continuaram a fornecer commodities para os países do Norte. Ironicamente, nas três últimas décadas, a entrada de países populosos, como China e Índia, no grupo das nações que mais provocam alterações nos subsistemas que compõe o Sistema Terra tem sido chamada por alguns de "democratização da destruição ambiental" (STEFFEN et al., 2011, p. 843). Essa "democratização" ameaça ainda mais as condições de habitabilidade do planeta nos próximos anos.

No que diz respeito aos efeitos catastróficos dos recentes incêndios de proporções inéditas que atingiram regiões tão distintas geograficamente como Austrália, Amazônia, Ártico, Califórnia - e poderíamos incluir o mais recente, no Pantanal - o jornalista e político canadense, Adam Vaughan (2019, p. 20-21) preconizou que vivemos na "Aurora do Piroceno" (Dawn of the Pyrocene). O alerta dado pelo secretário-geral das Nações Unidas, António Guterres (2020) é o mesmo: "Nosso planeta está queimando". E os cientistas já advertiram: a última década foi a mais quente desde que se iniciaram as medições.

Nesse sentido, já não é mais suficiente imaginar como nos prepararemos para o que vem, mas como lidar com o que está acontecendo agora. É esse o exercício de pensamento da antropóloga Anna Tsing na obra The Mushroom at the End of the Word: on the possibility of life in capitalist Ruins (2015). A partir de redes de colaboração que uma espécie de fungo estabelece com outras, a autora reflete sobre distintas possibilidades de viver sobre as ruínas do capitalismo (TSING, 2015). Nesse célebre trabalho, ela discute formas de sobrevivência e escapa da costumeira centralidade do "Humano" que caracteriza os discursos da sociologia, antropologia, filosofia, etc. 
Com efeito, tendo em conta que o termo Antropoceno para designar os efeitos das ações humanas teve sua origem entre químicos que investigam a atmosfera terrestre, e que o Capitaloceno foi proposto pelos que examinam as causas sociais de fenômenos atmosféricos, pode-se concluir que as duas abordagens mantêm mais uma relação de complementariedade do que de oposição. Latour vai mais longe e acrescenta que o nome Antropoceno não unifica, o Anthropos não significa um "ator dotado de consciência moral ou política" (2020, p. 196). Apesar do nome, o Antropoceno não deve ser tomado como "extensão imoderada do antropocentrismo [...]” (LATOUR, 2020, p. 197). Para o filósofo, a potência do termo é justamente "trazer a história de volta para o centro das atenções" (2020, p. 222), já que a ideia de uma só humanidade caminhando indefinidamente rumo ao progresso finalmente cai por terra. No Antropoceno, povos diferentes, indígenas, ribeirinhos, refugiados, quilombolas, habitantes das favelas e dos guetos se levantam para declarar que não são responsáveis pelo colapso ambiental, tendo suas histórias como prova de inocência.

\section{Urgências e Desafios para a criação do futuro no Antropoceno}

É possível se questionar: e no caso da sociedade capitalista globalizada? Como compreender essa volta "da história da para os centros das atenções"? O modelo teórico da "semântica dos tempos históricos", elaborado por Reinhart Koselleck (2006), pode fornecer uma importante chave de leitura para essa história. Publicado em 1979, Futuro-Passado analisa como uma determinada sociedade percebe a si mesma no presente a partir do tipo de articulação que mantém com seu passado. A noção de futuro, por sua vez, nutre-se do "horizonte de expectativas" formuladas no presente. Koselleck revela assim que as noções de passado, presente e futuro são categorias de pensamento e ação que inexistem fora de um sistema de significados (KOSELLECK, 2006). Na esteira de Koselleck, François Hartog examina as formas como o sistema de significados é simultaneamente moldado pela e modulador da história e, com isso, percebe a existência de distintos regimes de historicidade (HARTOG, 2019).

Enquanto o regime de historicidade moderno, que operou durante os séculos XVIII, XIX e boa parte do XX, exibiu certo otimismo e se caracterizou pela preeminência da ideia de futuro, alimentada pelo orgulho do progresso adquirido no passado, no regime de historicidade do Antropoceno a preeminência está na ideia de presente. É no presente que respondemos com urgência aos desafios que se apresentam. É no presente que lamentamos o passado, que lamentamos o que aconteceu e que não deveria ter acontecido. É no presente que procuramos o nome do erro que não pode ser computado a todos nas histórias humanas. Assim, este artigo aventa que o regime de historicidade do Antropoceno corresponde ao que Hartog (2019) chama de presentismo. Adentrar o Antropoceno parece então nos levar a operar na urgência, a exigir o descarte do passado como a experiência que nos conduziu até aqui, de forma que outros modos de se experimentar o mundo possam ser formulados a fim de se reivindicar um futuro, que não seja como o que atualmente se vislumbra, temível e 
assustador.

Nessa lógica, a Grande aceleração da metade do século XX não se restringiria à aceleração da predação do planeta e das alterações no Sistema Terra. O avanço acelerado do modelo de sociedade global capitalizada consumiu também o tempo histórico, isto é, o tempo percebido por meio das mudanças. Esse tempo que vem se acelerando pelo menos desde o século XVIII (o tempo da viagem a cavalo, do barco à vela, da troca de cartas, das feiras sazonais que por muitos anos determinou o ritmo da história) foi sendo encurtado pela tecnologia (KOSELLECK, 2006). Com isso, as descobertas, o descolamento, o envio de informações e até a transmissão de doenças contagiosas também se aceleraram. Assim, talvez a revolta dos adolescentes do Friday for Future, bem como os que defendem o decrescimento da economia global, os movimentos slow-food (em oposição à lógica fastfood), os que exigem respeito às diferenças de ritmo, de gênero, de modos de vida, de etnia, de seres vivos, etc. possam ser lidos como formas de resistir ao presentismo ou modos de criação do futuro. Mas por que o número dos resistentes não acompanha o aumento dos alertas científicos? O que é preciso para que mais pessoas exijam ser esse o ponto máximo da aceleração, que reivindiquem dos seus dirigentes que, daqui em diante, é imprescindível desacelerar?

Os documentos que alertam para o caráter emergencial da redução de gases do efeito estufa a partir de 2020 para que um aquecimento global desenfreado seja evitado são abundantes. Em 2017, 20 mil cientistas assinaram o manifesto The Scientist's Warning to Humanity: A Second Notice ${ }^{5}$ que definiu metas para o uso de energia, ocupação da terra, produção industrial, infraestrutura e finanças com o objetivo de tornar declinante as emissões de gases de efeito estufa a partir de 2020 e possibilitar o alcance efetivo das metas propostas no Acordo de Paris em $2015^{6}$. Dentre os 196 cenários em que o aquecimento global se mantém apenas $1,5^{\circ} \mathrm{C}$ acima da média do período Pré-Industrial projetados pelo relatório especial do IPCC (Painel Intergovernamental sobre Mudanças Climáticas) de 2018, "nenhum deles [...] admite que o pico de emissões de gases de efeito estufa (GEE) seja protelado para além de 2020" (MARQUES, 2020). Marques (2020) sublinha a importância do engajamento de cientistas, ativistas, políticos e diplomatas na chamada Missão 2020, mas aponta para o fato de que o ano de 2020 chegou e não houve arrefecimento efetivo, nem mesmo em meio à pandemia mundial de Covid-19. Pelo contrário, seguimos acelerando. Como convencer o público de que o aquecimento acima de $1,5^{\circ} \mathrm{C}$ pode provocar a exposição de quase 6 bilhões de pessoas ao calor intenso? Ou que um cenário na casa dos $2^{\circ} \mathrm{C}$ deixará 3,5 bilhões de

\footnotetext{
${ }^{4}$ Movimento internacional de estudantes, cujo expoente é Greta Thunberg, que não comparecem às aulas nas sextas-feiras para organizarem manifestações que exigem ações dos líderes políticos com o objetivo de evitar ou reduzir os efeitos das mudanças climáticas. $\mathrm{C} f$. < https://fridaysforfuture.org/>. Acesso em: 16 set. 2020.

${ }^{5} \mathrm{C} f$. $<$ https://mission2020.global/>. Acesso em: 30 set. 2020.

${ }^{6}$ Ver histórico dos encontros, acordos e tratados internacionais na página do órgão Convenção-Quadro das Nações Unidas sobre Mudanças do Clima (United Nations Framework Convention on Climate Change UNFCCC): < https://unfccc.int/process-and-meetings >. Acesso em: 16 set. 2020.
} 
pessoas sem acesso a recursos hídricos básicos? ${ }^{7}$ Ou de que, de agora em diante, doenças virais graves como o Covid-19 tendem a se proliferar com maior frequência (MARQUES, 2020)?

A lentidão na tomada de decisões políticas de grande escala é, sem dúvida, um grande impasse. A inabilidade (ou mesmo um desinteresse caracteristicamente presentista) de estabelecer um centro gestor internacional da questão climática capaz de realizar sanções faz com que as negociações entre Estados sejam marcadas pela recusa em assumir compromissos, por acusações de cargas desproporcionais de responsabilidade pelo colapso, por receio dos riscos econômicos advindos da desaceleração e por toda uma série de discursos que paralisam as ações e transformam em inalcançáveis as metas do Acordo de Paris. A COP25 (25 Conferência das Partes COP da Convenção-Quadro da ONU sobre Mudança do Clima), de 2019, realizada em Madri, "varreu definitivamente, em grande parte por culpa dos governos dos EUA, Japão, Austrália e Brasil, as últimas esperanças de uma diminuição iminente das emissões globais de GEE” (MARQUES, 2020).

Mas o problema não se restringe à ineficiência das macro-decisões geopolíticas. As lacunas entre atestados científicos e a opinião pública (que tem força para pressionar as instâncias legislativas e executivas) parecem estar se alargando. Uma crise de confiança atinge as principais instituições - política e ciência - capazes de fornecer orientações e ações para mitigar os efeitos do Antropoceno na vida das pessoas. Nesse sentido, a falsa controvérsia entre os cientistas que "acreditam" no aquecimento global de origem antrópica e os que se "opõem" a ele, alimentada pela mídia durante anos ${ }^{8}$, certamente contribuiu para a ascensão de discursos negacionistas como aqueles sustentados pelo presidente brasileiro, Jair Bolsonaro e o presidente norte americano, Donald Trump. Mas, estudos recentes como os de James Powell (2019) atestam que, mesmo que dois tipos de posicionamento científicos possam ter existido no passado, hoje a origem antrópica do real aquecimento global é consenso absoluto na comunidade científica.

Para a historiadora e filósofa da ciência Tatiana Roque, o questionamento do conhecimento científico e a incredulidade na eficácia da política em tornar a vida melhor são frutos do "fenômeno da pós-verdade", um processo que põe em xeque a crença nas benesses "das verdades que costumavam compor um repertório comum" (ROQUE, 2020). Assim, a crise de confiança atual reúne a falta de convicção nos sistemas políticos representativos e o rebaixamento das evidências e consensos científicos ao nível das convicções pessoais ou experiências vividas. Roque destaca que a pós-verdade "não designa apenas o uso oportunista da mentira" (2020), mas, sim, uma profunda desconfiança de que a ciência, a política, o sistema judiciário e tantas outras instituições que compõe o tecido social possam, de fato,

\footnotetext{
${ }^{7}$ Cf. $<$ https://www.ipcc.ch/site/assets/uploads/2019/07/SPM-Portuguese-version.pdf $>$. Acesso em: 1 out. 2020.

${ }^{8}$ A respeito dos interesses envolvidos na criação de dúvidas sobre o aquecimento global ver a obra ORESKES, Naomi; CONWAY, Erik. Merchants of Doubt: How a Handful of Scientists Obscures the Truth on Issues from Tobacco Smoke to Global Warming. New York: Bloomsbury, 2010.
} 
ajudar na resolução dos problemas cotidianos. Dessa forma, a filósofa e historiadora salienta que "não basta defender a ciência a partir de posições de autoridade, calcadas na superioridade ou na neutralidade do saber científico" (ROQUE, 2020). Pelo contrário, "sustentar uma verdade afirmando apenas que 'é comprovada cientificamente' pode reforçar a indiferença ou mesmo gerar irritação" (ROQUE, 2020).

Para mobilizar novos afetos é necessário que o diálogo entre cientistas e sociedade civil se amplie e que entrem em jogo argumentos que não se pautem apenas na autoridade cientifica. $\mathrm{O}$ convencimento das pessoas sobre a urgência da mudança nos modos de vida depende de promessas que demonstrem que as ciências estão abertas a críticas e autocríticas e que podem fornecer importantes ferramentas práticas e teóricas para atenuar os sacrifícios exigidos pelo Novo Regime Climático. É aqui que entra também a questão do ensino. Os objetivos da educação científica precisam se modificar para tentar responder às urgências do Antropoceno. Krenak critica profundamente o modelo de ensino que incentiva o utilitarismo e o funcionalismo.

\footnotetext{
Acho gravíssimo as escolas continuarem ensinando a reproduzir esse sistema desigual e injusto. O que chamam de educação é, na verdade uma ofensa à liberdade de pensamento, é tomar um ser humano que acabou de chegar aqui, chapá-lo de ideias e soltá-lo para destruir o mundo. [...] alguém nasceu, fez isso, fez aquilo, cresceu, fundou uma cidade, inventou o fordismo, fez a revolução, fez um foguete, foi para o espaço [...] Por que insistimos em tornar a vida uma coisa útil? Nós temos que ter a coragem de ser radicalmente vivos, e não ficar barganhando a sobrevivência. Se continuarmos comendo o planeta, vamos todos sobreviver por só mais um dia (KRENAK, 2020, p. 101-109).
}

As urgências desse Novo Regime Climático movimentam os laboratórios de engenharias, de biologia, de física, de química, etc. Projetos de restauração de ambientes em níveis regional e global estão sendo propostos por instituições de pesquisa espalhadas pelo mundo todo; ferramentas tecnológicas têm sido repensadas como meio de otimizar o uso dos recursos energéticos e a restauração de habitats. Alguns cientistas chegam a propor que para impedir a mutação climática é preciso transformar ainda mais e emitir deliberadamente aerossóis específicos que contrabalanceiem o aquecimento provocado pelos gases do efeito estufa (RASCH et al., 2008). Está cada vez mais claro que a garantia da habitabilidade do planeta no futuro próximo dependerá de esforços científicos. Nada disso, contudo, será eficaz sem que as ações da ciência sejam orientadas por uma nova concepção de riqueza e de coletividade que leve em conta a manutenção da reprodução de todas as formas de vida e não apenas do seleto grupo de homens investidores pertencente à alcunha humanidade.

\section{Considerações finais}

Mais do que apresentar ideias conclusivas, as análises e ponderações desenvolvidas ao longo deste artigo pretenderam indicar possíveis leituras acerca do complexo debate 
intelectual e científico que se desenha sobre o termo Antropoceno. Procurou-se evidenciar que os desafios relativos à formalização do Antropoceno e sua consequente inclusão na Escala do Tempo Geológico, como a época ulterior ao Holoceno, não podem ser enfrentados sem que questões da ordem da história humana - e, nesse sentido, sempre políticas - sejam também consideradas.

Não é difícil compreender o porquê das discussões sobre o Antropoceno terem se espalhado para além das fronteiras das chamadas ciências naturais e adentrado com força os debates políticos, ecológicos, culturais e filosóficos. Afinal, o problema do Antropoceno não se restringe a lançar olhares para o passado em busca do ponto histórico em que o projeto de sociedade moderna marcou de forma irreversível os estratos rochosos, comprometendo e alterando as condições holocênicas de habitabilidade do planeta. Embora esse gesto históricogeológico seja crucial para a compreensão do momento atual, é fundamental pensar sobre como atravessar da melhor forma possível tal época de mudanças das condições planetárias. Entendendo aqui que a "melhor forma possível" precisa abarcar os diversos tipos de humanidade e os diversos tipos de formas de vida.

Portanto, independentemente da formalização do Antropoceno ser reconhecida pelos membros da Comissão Internacional de Estratigrafia (ICS) e ratificada pela cúpula de profissionais que compõe a União Internacional das Ciências Geológicas (IUGS), refletir sobre essa nova época significa tomar parte no debate ético que desafia nossa forma de pensar a história e a ciência. Por sua urgência, o Antropoceno não nos permite esperar pelas gerações futuras de historiadores e cientistas para explicar e propor soluções para o presente medo do futuro.

\section{Referências bibliográficas}

CHAKRABARTY, D. O clima da História: quatro teses. (Publicado originalmente em Critical Inquiry, v. 35, 2009). Sopro 91, Florianópolis: Cultura e Barbárie, jul, 2013. Disponível em: <http://www.culturaebarbarie.org/sopro/n91s.pdf>. Acesso em: 16 set. 2020.

CHAKRABARTY, D. Anthropocene Time. History and Theory, v. 57, n. 1, p. 5-32, Mar. 2018.

CRUTZEN, P.; STOERMER, E. The Anthropocene. IGBP Global Change News, v. 41, p. $17-18,2000$.

CRUTZEN, P. Geology of Mankind. Nature, v. 415, p. 23, Jan. 2002.

DANOWSKI, D.; VIVEIROS DE CASTRO, E. Há mundo por vir? Ensaios sobre os medos e os fins. Florianópolis: Cultura e Barbárie e Instituto Socioambiental, 2014.

FINNEY, S. C.; EDWARDS, L. The Anthropocene epoch: scientific decision or political 
statement? GSA Today, v. 26, n. 3-4, p. 4-10, Mar. 2016.

GUTERRES, A. Temporada de incêndios na Austrália não foi normal: veja gráficos e entenda. Nações Unidas - Desenvolvimento Sustentável. 26 Fev. 2020. Disponível em: $<$ https://nacoesunidas.org/temporada-de-incendios-na-australia-nao-foi-normal-veja-graficose-entenda/>. Acesso em: 3 mai. 2020.

HARAWAY, D et al. Anthropologists Are Talking - About the Anthropocene in. Ethnos Journal of Anthropology, v. 81, n. 3, p. 535-564, 2016.

HARAWAY, D. Staying with the Trouble: Anthropocene, Capitalocene, Chthulucene. In. MOORE. J. W. (Org). Anthropocene or Capitalocene? Nature, History and the Crises of Capitalism. PM Press: Oakland, CA, 2016a. p. 34-77.

HARAWAY. D. Antropoceno, Capitaloceno, Plantationoceno, Chthuluceno: fazendo parentes. Tradução: Susana Dias; Mara Verônica; Ana Godoy. ClimaCom Vulnerabilidade, Campinas, ano 3, n. 5, 2016 b.

HARTOG, F. Regimes de historicidade: presentismo e experiências do tempo. Tradução: Andrea S. Menezes et al. Belo Horizonte: Autêntica Editora, 2019.

IPCC - PAINEL INTERGOVERNAMENTAL SOBR MUDANÇAS CLIMÁTICAS. Aquecimento Global de $1,5^{\circ} \mathrm{C}$. Contribuição dos Grupos de Trabalho I, II e III. Tradução: Mariane Arantes R. de Oliveira, 2018. Disponível em: <https://www.ipcc.ch/site/assets/ uploads/2019/07/SPM-Portuguese-version.pdf>. Acesso em: 20 set. 2020.

KLEBIS, D. Antropoceno, Capitaloceno, Cthulhuceno: o que caracteriza uma nova época? Clima Com Cultura Científica, Campinas, Out. 2014. Disponível em: $<$ http://climacom.mudancasclimaticas.net.br/?p=918>. Acesso em: 26 abr. 2020.

KOSELLECK, R. Futuro-Passado: contribuição à semântica dos tempos históricos. Tradução: Wilma Patrícia Maas; Carlos Almeida Pereira. Rio de Janeiro: Contraponto, Ed. PUC-Rio, 2006.

KRENAK, A. Ideias para adiar o fim do mundo. São Paulo: Companhia das Letras, 2019. KRENAK, A. A vida não é útil. São Paulo: Companhia das Letras, 2020. 
LATOUR, B. Diante de Gaia: oito conferências sobre a natureza no Antropoceno. Tradução: Maryalua Meyer. São Paulo/Rio de Janeiro: Ubu Editora/Ateliê de Humanidades Editorial, 2020.

LEWIS, S.; MASLIN, M. Defining the Anthropocene. Nature, v. 519 (7542), p. 171-180, Mar. 2015.

MALHI, Y. The Concep of the Anthropocene. Annual Review of Environment and Resources, v. 42, p. 77-104, 2017.

MARQUES, L. A pandemia incide no ano mais importante da história da humanidade. Serão as próximas zoonoses gestadas no Brasil? Ciência, Saúde e Sociedade: Covid-19. Campinas, 5 Mai. 2020. Disponível em: <https://bit.ly/2zUohnb>. Acesso em: 22 set. 2020.

MCBRIEN. J. Accumulating Extinction Planetary Catastrophism in the Necrocene. In: MOORE. J. W. (Org). Anthropocene or Capitalocene? Nature, History and the Crises of Capitalism. PM Press: Oakland, CA, 2016. p. 116-137.

McNEILL, J. R; ENGELKE, P. The Great Acceleration: An Environmental History of the Anthropocene since 1945. Cambridge, MA: Harvard University Press, 2014.

MILANEZ, F.; PINTO, M. dos S. Descolonizar a narrativa do Antropoceno: nego fugido e a liberdade socioecológica. In: ISSBERNER, L; LÉNA, P. Antropoceno: os desafios de uma "Nova Era". Boletim n. 38, ECOECO, jan-dez, 2019.

MOORE. J. W. (Org). Anthropocene or Capitalocene? Nature, History and the Crises of Capitalism. PM Press: Oakland, CA, 2016.

MOORE, J. The Rise of Cheap Nature. In: MOORE. J. W. (Org). Anthropocene or Capitalocene? Nature, History and the Crises of Capitalism. PM Press: Oakland, CA, 2016. p. 78-115.

ORESKES, N.; CONWAY, E. Merchants of Doubt: How a Handful of Scientists Obscures the Truth on Issues from Tobacco Smoke to Global Warming. New York: Bloomsbury, 2010.

POWELL, J. Scientists Reach 100\% Consensus on Anthropogenic Global Warming. In: Bulletin of Science, Technology \& Society, v.1-2, 2019.

RASCH, P; CRUTZEN, P; COLEMAN, D. Exploring the geoengineering of climate using stratospheric sulfate aerosols: the role of particle size. Geophysical Research Letters, v. 35, 
L. 02809, p. 1-6, Jan. 2008.

ROQUE, T. O Negacionismo no poder - questões da pós-verdade. Revista Piauí, ed. 161, Fev. 2020. Disponível em: <https://piaui.folha.uol.com.br/materia/o-negacionismo-nopoder/>. Acesso em: 30 set. 2020.

SCHELLNHUBER, H. J. Earth System Analysis and the Second Copernican Revolution. Nature, v. 402, suppl, p. 19-23, Dec. 1999.

SMITH, F.; LYONS, R.; PAYNE, J. Body size downgrading of mammals over the late Quaternary. Science, v. 360 (6386), p. 310-313, 2018.

STEFFEN, W.; CRUTZEN, P.; MCNEILL, J. The Anthropocene: Are humans now overwhelming the great forces of nature? Ambio - a journal of the human environment, $v$. 36, n. 8, p. 614-621, Dec. 2007.

STEFFEN, W; GRINVALD, J; CRUTZEN, P; MCNEILL, J. The Anthropocene: conceptual and historical perspectives. Philosophical Transactions - a journal from The Royal Society, v. 369, p. 842-876, Jan. 2011.

STENGERS, I. No tempo das catástrofes - resistir à barbárie que se aproxima. Tradução: Eloisa Araújo. São Paulo: Cosac Naify, 2015.

TSING, A. The Mushroom at the End of the World: on the possibility of life in Capitalist Ruins. Princeton: Princeton University Press, 2015.

VAI, G. B. The Second International Geological Congress, Bologna, 1881. Episodes, v. 27, n. 1, p. 13-20, Mar. 2004.

VAUGHAN, A. Dawn of the pyrocene. New Scientist, p. 20-21, Aug. 2019.

VEIGA, J. E. da. Antropoceno e a Ciência do Sistema Terra. São Paulo: Editora 34, 2019.

WATERS, C. et al. The Anthropocene is functionally and stratigraphically distinct from the Holocene, Science, v. 351, Issue 6269, p.137-49, Jan. 2016.

WATERS, C. et al. Global Boundary Stratotype Section and Point (GSSP) for the Anthropocene Series: Where and how to look for potential candidates. Earth-Science Reviews, v. 178, p. 379-429, Mar. 2018. 
ZALASIEWICZ, J. et al. The technofossil record of humans. The Anthropocene Review, v. I, p. 34-43, 2014.

ZALASIEWICZ, J. et al. The Working Group on the Anthropocene: Summary of Evidence and Interim Recommendations. Anthropocene, v. 19, p. 55-60, Set, 2017. 